Paul R. Mullins

\section{The Rhetoric of Things: Historical Archaeology and Oral History}

\begin{abstract}
This paper examines precisely how objects assume meanings in archaeological interpretation and a dimension of everyday life and experience that exists on the fringes of self-consciousness. Archaeologists interpret the meanings of material things in ways that have often sought to erase the ambiguities of material symbolism in conventional linear narratives, but oral memories routinely struggle with the meaning of things and underscore their complex and ambiguous meanings. The paper examines how the contributors to this volume illuminate the implications of oral memories on broader material culture scholarship both within and beyond historical archaeology.
\end{abstract}

\section{Talking About Things}

Archaeologists eternally wrestle with the question of what things mean, continually contextualizing objects to weave an articulable narrative about those things. Those archaeological narratives most often speak to broad social processes or contextual scales encompassing anything from ethnic distinction to global capitalism. Yet much of the human experience of urbanity, consumer society, or globalization was itself on the borders of everyday conscious apprehension, just as most objects occupy a paradoxically intimate yet unexamined position in people's everyday lives. It is that liminality of material meaning that lies at the heart of oral memory, which shares with archaeological narrative a struggle to articulate the meaning of the most familiar things.

Flummoxed by such liminality, oral histories of things routinely descend into a description of idiosyncratic experiences-where a sofa was purchased, why a shirt in a particular color is favored, or who was the provider of an heirloom-or rather prosaic functional analyses of things - the stoneware vessel that is an ideal size for churning butter, what Doan's Pills did, how a fountain pen was loaded with ink.
Things reside at the heart of people's lives, but they provide a distinctively ambiguous rhetorical voice in oral history that runs somewhat counter to archaeology's ambition to craft systematic narrative. Nevertheless, oral testimony's struggle to capture material meanings is not at all antithetical to archaeological narrative, and we as historical archaeologists might use such oral memories most productively if we actually try to preserve their ambiguity and acknowledge that such ambiguity is central to the meaning of things as well.

Many material things make a claim for the power of materiality, oral testimony, and textual narratives, but there are few more interesting, if unexpected, archaeological parallels than scrapbooks. A scrapbook is a self-made document of one's life with the prosaic material items at hand, like photographs, ticket stubs, dried flowers, report cards, and comparably mundane material things woven into life stories. A scrapbook aspires to be a coherent narrative arranged in ways that define the narrator, while it simultaneously tells that story with little or no text; instead, the concrete objects themselves evoke memories and attest to the meaningfulness of a life experience. A scrapbook acknowledges the incoherence of everyday life, but attempts to impose a coherent and meaningful narrative on life, and in this sense it shares quite a lot with oral testimony and textual narratives that likewise try to "make sense" of the material world. Like archaeological narratives, scrapbooks are exceptionally powerful because they appropriate everyday material "scraps" with the confidence that such prosaic things can, however obliquely, tell the most consequential stories about their narrators across time: a placemat from a vacation trip, a letter of recognition, or a dried prom corsage can underscore the consequence of one person's experience more than a conventional autobiographical narrative (Katriel and Farrell 1991).

A thing in a scrapbook evokes a life experience without necessarily fathoming what that narrative means, or it makes sense of that experience only in hindsight and with the 
weight of an assemblage of things collectively attesting to that experience. Things in scrapbooks typically reference particular moments, but they are valued by narrators because the things in a scrapbook are perceived as painting a powerful but largely unspoken picture of a social subject. Like archaeologists, museum curators, or collectors, scrapbook narrators grasp the rhetorical power of things and try to make them "come to life" in particular ways that counter the alienation of their narrators. People routinely struggle to cast imponderable things in ways that will impose coherence on a largely unarticulated and de-centered life. A scrapbook's narrator, for instance, often hopes the document will attest to a life "well-lived" (Katriel and Farrell 1991:5). Yet the slippages between intended meanings and experienced substance contain some of the most challenging analyses of materiality (Plotz 2005:110).

Things may well trigger discussion by reviving vague memories or simply posing ambiguous meanings, and oral expression of material meaning often illuminates the complicated intersection of emotion, experience, conflict, and consciousness that shapes materiality and memory. The challenge is that material things can be enormously uncooperative because of their powerful symbolic ambiguities, and because they can evoke a wide range of problematic meanings. For much of the last half millennium, things have often caused people anxiety: 18th- and 19th-century "it-narratives," for instance, routinely gave voice to commonplace objects that exposed their possessors as vain and selfish (Trentmann 2009:293). Written in an historical moment in which captivity, patriarchy, impoverishment, and colonialism made people objectify their own labor, thoughts, and selves, and question what it meant to be human, it-narratives used the most mundane things, like buttons and coins, to comment on that humanity (Freedgood 2010). Scrapbooks aspire to place such intimate, conflicted objects in a narrative framework that rinses them of unsettled meanings and, instead, serves an optimistic and coherent narrative; where scrapbooks give things a utopian, if somewhat idealistic voice, the voices of things in "it-narratives" were often sober, pessimistic, or even dystopian.

In 1787, for instance, The Adventures of a Silver Penny told the tale of a commonplace coin that began with its origins in "a mine in
Peru, in South America, distant from our own country upwards of five thousand miles. See how hard the poor slaves are at work in it" (Johnson 1787:8). An accompanying illustration of captive laborers producing the penny's matter starkly countered the fetishized meanings of the coin in British hands, acknowledging that the "Spaniards, to whom this gold and silver country now belongs, in order to get possession of it murdered innumerable thousands of innocent Indians, and made slaves of those they did not murder" (Johnson 1787:9-10). The little coin launched into a surprisingly stiff critique of consumer society:

\footnotetext{
That nice silver spoon, with which you eat your milk for breakfast, and the pretty silver cup, out of which you drink your beer at dinner time, originally came from that distant place I have just mentioned, and were dug out of the bowels of the earth, at the expence of the death of thousands, and the slavery of many more. I should tell you, my pretty readers, that in the early ages of the world, there were no such things as trade and commerce, and consequently money was then unknown. In those days, people used to exchange one necessary for another and the richest man was he who was most industrious in the cultivation of his lands, and in the improvement of his flocks and herds (Johnson 1787:10-11).
}

In this and many more "it-narratives," things expressed their meanings beyond the hands of a single consumer and circumspectly addressed the apprehensions many people had about consumer desire, globalization, and materiality.

Perhaps nothing confirms the relevance of things more than the struggles to express the meanings of materiality, whether they be in oral testimony, text, or aesthetics. We as historical archaeologists have routinely painted a symbolically rich world evoking intersections of empire and locality, self and other, or household and marketplace, a powerful interpretive narrative that is inevitably more systematic and symbolic than nearly any oral-historical account. Oral histories paradoxically place things at the heart of memories while casting their meanings clumsily; that is, like most scrapbook narrators, we have undeniably strong feelings about things, and objects can energize powerful memories, but we often struggle to articulate those meanings, unable to capture the depth of consequence invested in things like chocolate, family pictures, neighborhood spaces, everyday china, and myriad other prosaic things. The meaning of some goods is 
simply beyond satisfying expression, and oral testimony, archaeological textuality, and social practices like scrapbooking struggle to capture essential dimensions of those meanings that may well be otherwise unarticulated and unrecognized.

Oral histories have been used thoughtfully and creatively in virtually every social science, but oral testimony that focuses on things raises two distinctive questions. First, how do people orally express the meaning of things in particular ways that aspire to capture their rich emotional, aesthetic, personal, and tactile qualities? Material meanings are expressed in various ways in texts, oral testimony, and everyday experience, but specifically what distinguishes oral testimony about things, and how can this testimony expand archaeological interpretation? Archaeology secures much of its rhetorical power from mute, ambiguous, and symbolically powerful things, but that ambiguity is often effaced in conventional analytical discourses; that is, in archaeology and broader scholarship, the mute landscape of everyday things has often been reduced to its most narrow functional meanings, rendering things simply as representational symbolic objects laden with signification tapped and articulated by a reflective scholar. Oral memories produce very distinctive constructions of material meaning - much more circuitous, personal, and emotive - that can significantly extend historical archaeology's conventional textual narratives.

Second, are there culturally, socially, and classspecific ways of articulating material symbolism? There is strong evidence for socially specific consumer patterns grounded in a range of class, cultural, and social factors, so the ways people articulate those meanings must be distinctive as well. For instance, is there a distinctly British framework for materiality rooted in culturally and regionally specific subjectivities? There may be a distinctively British depth to or distinctive experience of memory that separates it from how many Americans approach heritage and the historicity of material things. Yet a creamware chamber pot is still objectively the same physical object regardless of context, and while consumers project distinctive meanings onto such things, they still have a uniform materiality that must have some impact on every consumer.

Like texts, oral histories hope to capture the meaning of things, but unlike texts they often break from linear narrative and rhetorical conventions, and reveal the complicated physical and symbolic depths of even the most prosaic things. That oral testimony about things and the ways memory is articulated in relation to objects is clearly shaped by the way a memoirist interacts with an object. For instance, Webster, Tolson, and Carlton (this issue) underscore the ways people corporeally interact with things and articulate their meanings, acknowledging that a fragmentary artifact and a whole object produce distinctive responses. Webster, Tolson, and Carlton outline an archaeological imagination of material meaning that breaks from the ways most people conceive of things; that is, archaeologists expect a material world of incomplete things, fragmented objects, and sherds that are meaningful as fragments or as representatives of a whole thing, but elders in the Ovenstone Project were puzzled by fragmentary archaeological remains. The Ovenstone Project has spent much of its subsequent oral-historical conversation using complete objects, rather than fragmented things, as memory "triggers." Likewise, Casella and colleagues (this issue) stress that oral testimony is very different in an archaeological landscape than it is in a memoirist's living room.

These new approaches give things agency, examining how objects themselves shape oral testimony when given an "active role" in interpretation. The women in Webster, Tolson, and Carlton's interviews, who discussed distinctively bent spoons, collectively recognized that their fathers and grandfathers all had shaped spoons this way for home manufacture of lead fish weights. That example reveals how oral testimony illuminates idiosyncratic patterns, and the elder women in those conversations likely had not reflected on such practices until they inspected an archaeologically excavated spoon, indeed, these women may never have articulated the practice as anything more substantial than one of countless everyday material patterns, so the literal knowledge of the practice was not articulated in narrative terms until archaeologists illuminated the things.

The most consequential implication of the bent-spoon story is that objects may be more effective mechanisms to "conduct" an oralhistorical interview than a person, especially when groups of memoirists use objects to discuss their personal and shared experiences. 
The agency of material culture is very much shaped by the literal bodily interaction with things, which has clear implications for how archaeologists conduct interviews on materiality. Carlton and Richard (this issue) indicate that most archaeological applications of oral history use personal testimony to refine the historical picture of an archaeological context, but such a methodology risks ignoring that oral history can paint a particularly distinctive picture of materiality. Archaeological oral histories tend to reach other scholars as snippets of text woven into a systematic narrative, but we as scholars have no concrete way to describe the corporeal interaction of people and things in oral-history interviews, and few if any archaeologists have devoted much reflection to even seeing such interaction with things as itself a source of insight. The richest archaeological oral histories are likely to use things themselves as physical and emotional departure points for distinctive memories that break from conventional oralhistorical accounts of a generalized past.

Webster, Tolson, and Carlton examine how things can guide oral memoirists, but Allison examines a more loosely structured narrative framework in which archaeologists focus on everyday discussions outside the confines of oral interviews. Her Australian project gleaned insights from a breadth of random conversations and structured interviews, framing oral history less as a single component of the project than an ethnographic dimension of the entire research process, and, by placing such ethnographic method at the heart of the project's research, she argues that it provides more equity between community stakeholders and archaeologists. Certainly most archaeologists have such ethnographic encounters by chance in the course of fieldwork, but scholars increasingly work to create the potential for those encounters and relationships as a part of their research (Atalay 2006; Castaneda and Matthews 2008; Hammilakis and Anagnostopoulos 2009). Lynn Meskell (2005) champions just such an "improvisational" ethnography, yet she stresses that such contextually specific ethnographic insight must always be a conscious dimension of project methodology and not simply a serendipitous chat with a thoughtful community member. Indeed, oral historians often prepare separate chapters for technical reports or have a genuine division of labor on a project that separates them from the scholars who dig sites, analyze artifacts in the lab, write reports, and teach archaeological research. The movement toward an ethnographic archaeology champions turning all field archaeologists into ethnographers and embracing an interdisciplinarity long-accepted in theory, but not always embedded in practice.

The most challenging philosophical and methodological dimensions of material rhetoric perhaps revolve around the archaeological discourses that interpret things. Archaeology aspires to cast interlocking material and cultural worlds in coherent rhetorical terms that render mostly unspoken individual, communal, or global experiences in concrete descriptive terms. Those systematic narratives might examine the global colonial systems and consumer networks that bound together people with no conscious recognition of their relationships; they could focus on the functional and aesthetic makeup of material assemblages and comparisons between patterns in the assemblages of everyday things; or they may attempt to express the distinctive way in which a social or cultural collective defines particular material things. Archaeology will always be wed to textuality, but such narratives can be profoundly enriched by oral accounts of materiality, because the idiosyncratic clumsiness of oral narrative underscores that things exist on the margins of thought, language, and experience.

When we as archaeologists write about and discuss things, it is not entirely clear what such narratives are interpreting. Social scientists regularly applaud the "material turn" taken since the 1980 s, but that renewed focus on material symbolism may have, oddly enough, looked past things themselves and instead revolved around consumption and the social meanings projected onto materiality. Bjornar Olsen's (2003) maddeningly clever warning is that perhaps we have not returned to things at all, despite all the newfound interest in materiality; we have focused our attention on the relationship among people, materiality, and the social construction of material symbolism, but we have yet to actually grasp things in themselves. A thing in a scrapbook assumes meaning outside textuality, and it exists in a physical interaction with people that challenges rhetorical expression, but Olsen argues that most scholarly attention has focused on how meaning is socially constructed 
for things and has failed to wrestle with the very corporeality of things.

Historical archaeologists use oral testimony in a wide range of ways, but it may provide its most important contributions, not in resolution of questions or clarification of context, but in its capacity to fuel socially productive discussions. Oral histories are most often meant to resolve contradiction and eliminate interpretive errors, rather than struggle over those contradictions. In the former case, oral histories are wielded as clarifying mechanisms that provide correctives to primary records or amplify the social meaning of an artifact or practice. This approach uses oral testimony to establish a richer range of facts for an archaeological interpretation, ideally pinning down the meanings of objects or contextualizing them in ways archaeological assemblages alone do not reveal. This is a useful and powerful way to use oral memory, yet in a rush to discard all the stultifying descriptive mechanics of scientific rigor, perhaps archaeologists have sometimes socialized things so thoroughly that they no longer actually appear in archaeological interpretation (Olsen 2007:582). Things may have a certain ambiguity of meaning, but they can provide exceptionally concrete starting points for discussion, and much of the most challenging archaeology uses prosaic things to trigger discussion on consequential issues that are otherwise not confronted.

\section{Acknowledgments}

Thanks to Jane Webster and Louise Tolson for including me in the Newcastle conference and sharing their research with me. My research in Newcastle in 2011 was supported by a Newcastle University Faculty of Humanities and Social Sciences Visiting Fellowship. My initial visit to Newcastle in 2010 was made possible by an Indiana University New Frontiers in the Arts and Humanities Exploration Traveling Fellowship. Thanks to the faculty and colleagues at Newcastle who made my visit pleasant and productive, especially Louise Tolson, Sam Turner, Jane Webster, and Rob Young. Any problems in this paper are of my own doing.

\section{References}

Atalay, Sonya

2006 Indigenous Archaeology as Decolonizing Practice. American Indian Quarterly 30(3\&4):280-310.

Castaneda, Quetzil E., and Christopher Matthews (EDITORS)

2008 Ethnographic Archaeologies: Reflections on Stakeholders and Archaeological Practices. AltaMira Press, Lanham, MD.

FreEdGoOd, Elaine

2010 What Objects Know: Circulation, Omniscience and the Comedy of Dispossession in Victorian It-Narratives. Journal of Victorian Culture 15(1):83-100.

Hammilakis, Yannis, and Aris Anagnostopoulos

2009 What is Archaeological Ethnography? Public Archaeology 8(2\&3):65-87.

JOHNSON, RICHARD

1787 The Adventures of a Silver Penny, including Many Secret Anecdotes of Little Misses and Masters both Good and Naughty. E. Newbery, London, UK.

Katriel, TAMAR, AND Thomas Farrell

1991 Scrapbooks as Cultural Texts: An American Art of Memory. Text and Performance Quarterly 11(1):1-17.

Meskell, LyNN

2005 Archaeological Ethnography: Conversations around Kruger National Park. Archaeologies 1(1):81-100.

Olsen, BJORnAR

2003 Material Culture after Text: Re-Membering Things. Norwegian Archaeological Review 36(2):87-104.

2007 Keeping Things at Arm's Length: A Genealogy of Asymmetry. World Archaeology 39(4):579-588.

Plotz, John

2005 Can the Sofa Speak? ALook at Thing Theory. Criticism 47(1):109-118.

Trentmann, Frank

2009 Materiality in the Future of History: Things, Practices, and Politics. Journal of British Studies 48(2):283-307.

Paul R. Mullins

Department of Anthropology

INDIANA UNIVERSITY-

Purdue University, Indianapolis

Cavanaugh Hall 413B

INDIANAPOLIS, IN 46202 